\title{
Is adjuvant radiotherapy necessary for FIGO stage 1a grade 2 endometrial endometrioid adenocarcinoma?
}

\author{
Abdurrahman Hamdi İnan', Gülçin Şahin Ersoy², Yusuf Yıldınım³, Tutku Gürbüz', Ayşe Gül Kebapçılar', Merih Hanhan ${ }^{5}$ \\ ${ }^{\prime}$ Clinic of Obstetrics and Gynecology, Ardahan State Hospital, Ardahan, Turkey \\ ${ }^{2}$ Department of Obstetrics and Gynecology, Marmara University Pendik Training and Research Hospital, Istanbul, Turkey \\ ${ }^{3}$ Department of Obstetrics and Gynecology, Divison of Gynecologic Oncology, Erzincan University Faculty of Medicine, \\ Erzincan, Turkey \\ ${ }^{4}$ Department of Obstetrics and Gynecology, Selçuk University Faculty of Medicine, Konya, Turkey \\ ${ }^{5}$ Clinic of Obstetrics and Gynecology, Divison of Gynecologic Oncology, İmir Aegean Obstetrics and Gynecology \\ Education and Research Hospital, Izmir, Turkey
}

\section{Abstract}

Objective: The impact of adjuvant radiotherapy on the rates of survival and local recurrence was analyzed in patients diagnosed with International Federation of Gynecology and Obstetrics (FIGO) stage 1a grade 2 endometrial endometrioid adenocarcinoma.

Material and Methods: Medical records of 82 patients diagnosed and treated for FIGO stage la grade 2 endometrial endometrioid adenocarcinoma were reviewed retrospectively. A group of 59 patients who received postoperative radiotherapy was compared with a control group of 23 subjects treated without adjuvant radiotherapy; the duration of survival as well as the local recurrence and metastasis rates were evaluated in both groups.

Results: The analysis of patient data has revealed the rate of local recurrence as $4.3 \%$ vs. $1.7 \%(\mathrm{p}=0.485)$, the rate of distant metastasis as $4.3 \%$ vs. $6.9 \%(\mathrm{p}=1.000)$, and the mean survival time as $83.6 \pm 38.7$ vs. $81.5 \pm 37.5$ months $(\mathrm{p}=0.828)$ in the adjuvant radiotherapy and control groups, respectively.

Conclusion: In the presented study, adjuvant radiotherapy failed to improve the overall survival of the patients in the low-risk group (stage la grade 2). With the addition of the significant risk of radiation toxicity, it is highly probable that these patients will not benefit from postoperative radiotherapy. Close observation should be performed following the primary surgery in this patient group. Nevertheless, it should also be considered that adjuvant radiotherapy is a very effective treatment modality for the recovery of patients with vaginal relapse. (J Turk Ger Gynecol Assoc 2015; 16: 153-7)

Keywords: Endometrial cancer, adjuvant radiotherapy, mean survival time

Received: 23 September, $2014 \quad$ Accepted: 14 May, $2015 \quad$ Available Online Date: 14 July, 2015

\section{Introduction}

Endometrial carcinoma is the most frequently observed gynecologic malignancy in developed countries. The symptoms generally arise early in the course of the disease; therefore, despite the high incidence and the lack of effective screening tests, more than $80 \%$ of the cases are diagnosed at an early stage when full recovery is generally possible with surgical intervention only (1-4). At the time of diagnosis, approximately $68 \%$ of patients present with localized disease, $20 \%$ with metastasis to the regional lymph nodes, and $8 \%$ with distant metastasis. The overall 5 -year relative rates in these patients are $96 \%, 67 \%$, and $16 \%$, respectively (5).

The major prognostic factors of the endometrial carcinoma are as follows: metastasis to lymph nodes, surgical stage, grade, myometrial invasion depth, and histological types (6). These risk factors facilitate the classification of the patients according to the recurrence rates and most suitable adjuvant therapy alternatives. The randomized studies have revealed that adjuvant radiotherapy has decreased the local recurrence rates in endometrial cancer without any significant contribution to the survival rates of patients with this disease (7). There have been numerous studies conducted on adjuvant radiotherapy for early-stage endometrial cancer confined to the uterus; however, the optimal treatment approach is still controversial (7-9). In this study, the impact of the adjuvant radiotherapy on the survival rate and local recurrence was analyzed in patients diagnosed with stage la grade 2 endometrial endometrioid adenocarcinoma.

\section{Material and Methods}

Medical records of patients diagnosed with endometrial endometrioid adenocarcinoma and treated in the gynecologic oncology department between August 2002 and January 2014 were reviewed retrospectively. The staging of patients

Address for Correspondence: Gülçin Şahin Ersoy, Marmara Universitesi Pendik Eğitim ve Araştırma Hastanesi, Kadın Hastalıkları ve Doğum Anabilim 
operated before 2009 had been performed according to the 1988 International Federation of Gynecology and Obstetrics (FIGO) criteria (10); the surgical details of these patients at the time of the operation were reconsidered according to the 2009 FIGO criteria and the staging of these patients has been updated. Patients with a type of endometrial cancer other than endometrial endometrioid adenocarcinoma, with a surgical stage other than stage 1a, with a histological grade of 1 and 3, patients with missing data, and patients lost in the follow-up period have been excluded from the study. A total of 82 patients with a diagnosis of FIGO stage 1a and a postoperative histological grade of 2 have been included in the study.

Radiotherapy started after wound healing (after 4-8 weeks from operation). Of the 59 patients, 19 received postoperative external pelvic radiotherapy via the three-field or four-field box technique or three-dimensional conformal radiotherapy (3DCRT) technique alone at a total dose of 4500-5000 cGy using Primus Linac (Siemens medical systems, Concord, California, United States) or Theratron 780E (MDS Nordion, Ontario, Canada) or Therasim 750 simulator (A.E.C.L., Ontario, Canada) or Axsim (Mecaserto, Vignes, France) in 20-25 daily fractions to the pelvis. 13 cases received intracavitary radiotherapy alone [ $3 \mathrm{x} 400 \mathrm{cGy}$ at $0.5 \mathrm{~cm}$ over 3-7 days at high dose rate or a total dose of $1500 \mathrm{cGy}$ at low dose rate (50 cGy per hour) ]Twentyseven patients received intracavitary radiotherapy after external beam radiotherapy. According to the application of postoperative radiotherapy, the patients have been divided in two groups. In both groups, the duration of survival as well as recurrence and metastasis rates were evaluated. Age, comorbidities, parity, timings of menarche and menopause, surgical stage, histological grade, tumor size, survival, cytological analysis of peritoneal lavage, application of adjuvant radiotherapy, localization, and handling of recurrence if present were recorded as the main outcome measures. The study has been conducted in accordance with the Declaration of Helsinki and approved by the local ethics committee.

The Statistical Package for the Social Sciences (SPSS) v20.0 software (SPSS Inc., Chicago, Illinois, Unites States) has been used for the analysis of data. All data have been given in percentages, median, or mean \pm standard deviation (SD). Mann-Whitney U test and independent sample t test have been applied for the comparison of the two groups. Fischer's exact test has been utilized if conditions for chi-square test were not met. KaplanMeier life tables were used to calculate survival; log rank test was used for comparison of survival curves. Overall survival is defined as the time from random assignment to death as a result of any cause. In addition, the disease-free survival is determined as the length of time after treatment during which no recurrence or metastasis is found (6). The results were reported with a confidence interval of $95 \%$, and p value $<0.05$ was considered as statistically significant.

\section{Results}

The group of patients without radiotherapy consisted of 23 cases with an average age of $56.6 \pm 9.5$ years (between 39 and 71 years), whereas the group of patients with radiotherapy
Table 1. The distribution of the main reproductive and characteristic data of subjects in each group

\begin{tabular}{|c|c|c|c|}
\hline & $\begin{array}{l}\text { Patients without } \\
\text { radiotherapy } \\
(n=23) \\
\text { mean } \pm \text { standard } \\
\text { deviation }\end{array}$ & $\begin{array}{l}\text { Patients with } \\
\text { radiotherapy } \\
(n=59) \\
\text { mean } \pm \text { standard } \\
\text { deviation }\end{array}$ & $\mathbf{p}$ \\
\hline Age & $56.6 \pm 9.5$ & $57.7 \pm 7.7$ & 0.589 \\
\hline Age of menarche & $12.8 \pm 1.2$ & $13.2 \pm 1.6$ & 0.214 \\
\hline Age of menopause & $49.3 \pm 5.2$ & $48.4 \pm 5.4$ & 0.502 \\
\hline Parity* & 2 & 3 & 0.297 \\
\hline$<60$ years $(\mathrm{n})$ & 15 & 39 & 0.940 \\
\hline$>60$ years $(n)$ & 8 & 20 & \\
\hline
\end{tabular}

Table 2. The distribution of comorbidities in each study group

\begin{tabular}{|l|c|c|}
\hline Comorbidities & $\begin{array}{c}\text { Patients without } \\
\text { radiotherapy } \\
\text { (n=23), } \\
\text { (n, \%) }\end{array}$ & $\begin{array}{c}\text { Patients with } \\
\text { radiotherapy } \\
\text { (n=59), } \\
\text { (n, \%) }\end{array}$ \\
\hline Diabetes mellitus & $7(30.4)$ & $10(16.9)$ \\
\hline Hypertension & $6(26.1)$ & $22(37.3)$ \\
\hline Breast cancer & $1(4.3)$ & $3(5.2)$ \\
\hline Infertility & $0(0.0)$ & $2(3.4)$ \\
\hline Thyroid disorder & $0(0.0)$ & $1(1.7)$ \\
\hline Cirrhosis & $1(4.3)$ & $0(0.0)$ \\
\hline Varice & $1(4.3)$ & $0(0.0)$ \\
\hline Heart disease & $3(13)$ & $4(6.9)$ \\
\hline Familial mediterranean fever & $1(4.3)$ & $0(0.0)$ \\
\hline
\end{tabular}

included 59 subjects with an average age of $57.7 \pm 7.7$ years (between 39 and 75 years). The main reproductive data of all patients is summarized in Table 1.

The analysis of comorbidities in study groups has revealed that the most frequent illnesses in the groups of subjects with and without radiotherapy were hypertension and diabetes mellitus, respectively (Table 2 ).

The postoperative evaluation of the surgical specimens has revealed that the mean size of the tumor was greater in the group of patients with adjuvant radiotherapy $(31.6 \pm 16.2 \mathrm{~mm}$ vs. $27.5 \pm 12.9 \mathrm{~mm} ; \mathrm{p}=0.436)$. However, neither this finding nor the comparison of the lymph node dissection rates between the two groups has yielded a statistically significant difference (Table 3).

The rates of recurrence and metastasis have shown no significant difference between the two groups (Table 4); however, remarkably, none of the patients with distant metastasis have demonstrated local recurrence. The comparison of both groups for survival and mortality rates has revealed similar results (Table 4).

Disease-free survival rate was similar in the postoperative radiotherapy group (91.5\%) when compared to no treatment group 
Table 3. The distribution of lymph node dissection rates, tumor sizes, LVSI, and type of adjuvant radiotherapy

\begin{tabular}{|c|c|c|c|}
\hline & $\begin{array}{c}\text { Patients without } \\
\text { radiotherapy } \\
\text { (n=23), } \\
\text { (n, \%) }\end{array}$ & $\begin{array}{c}\text { Patients with } \\
\text { radiotherapy } \\
\text { (n=59), } \\
\text { (n, \%) }\end{array}$ & p \\
\hline Paraaortic LND & $12(52.2)$ & $26(44.1)$ & 0.508 \\
\hline Pelvic LND & $17(73.9)$ & $47(79.7)$ & 0.572 \\
\hline Tumor size ${ }^{\mathrm{a}}$ & $27.5 \pm 12.9$ & $31.6 \pm 16.2$ & 0.436 \\
\hline$<20$ mm & $7(30)$ & $11(21)$ & \\
\hline$>20$ mm & $16(70)$ & $48(79)$ & \\
\hline LVSI & $4(18)$ & $17(29)$ & 0.565 \\
\hline Positive & $16(69)$ & $35(59)$ & \\
\hline Negative & $3(13)$ & $7(12)$ & \\
\hline Unknown & & & \\
\hline Radiotherapy & 19 & & \\
\hline ERT & 27 & & \\
\hline ERT+ICRT & 13 & & \\
\hline ICRT & & & \\
\hline
\end{tabular}

aMean \pm Standard deviation, millimeter

ERT: external pelvic radiotherapy; ICRT: intracavitary radiotherapy;

LVSI: lymphovascular space invasion; LND: lymph node dissection

Table 4. The rates of reccurrence, metastasis, and mortality rates among the groups and the comparison of mean duration of survival between the study groups

\begin{tabular}{|c|c|c|c|}
\hline & $\begin{array}{l}\text { Patients without } \\
\text { radiotherapy } \\
(n=23)\end{array}$ & $\begin{array}{l}\text { Patients with } \\
\text { radiotherapy } \\
(n=59)\end{array}$ & $\mathbf{p}$ \\
\hline Recurrence $^{\mathrm{a}}$ & $1(4.3 \%)$ & $1(1.7 \%)$ & 0.485 \\
\hline Metastasis $^{\mathrm{a}}$ & $1(4.3 \%)$ & $4(6.9 \%)$ & 1.000 \\
\hline Mortality rate $^{\mathrm{a}}$ & $0(0 \%)$ & $2(3.4 \%)$ & 1.000 \\
\hline Survival (months) ${ }^{\mathrm{b}}$ & $83.6 \pm 38.7$ & $81.5 \pm 37.5$ & 0.828 \\
\hline
\end{tabular}

(91.3\%) $(\mathrm{p}=0.945)$, There was also no statistically significant difference for the 5 -year overall survival rates between the groups ( $96.6 \%$ and $100 \%$, respectively, $\mathrm{p}=0.382$ ). The diseasefree survival and 5-year overall survival Kaplan-Meier curves are shown in Figure 1, 2.

\section{Discussion}

Currently, the staging of endometrial cancer is performed according to the FIGO guidelines updated in May 2009. The standard staging procedure consists of the evaluation of peritoneal lavage, total extrafascial hysterectomy, bilateral salpingo-oophorectomy, and pelvic and para-aortic lymph node dissection specimens (11). The role of postoperative radiotherapy in low-risk early-stage endometrial cancer has been investigated in many studies, and
Table 5. Randomized articles about adjuvant $R T$ in women with low-risk stage 1 endometrial cancer and trial characteristics

\begin{tabular}{|l|c|c|c|c|c|}
\hline & $\begin{array}{c}\text { Patients } \\
\text { (n) }\end{array}$ & AdjRT & $\begin{array}{c}\text { Follow-up } \\
\text { (years) }\end{array}$ & $\begin{array}{c}\text { Recurrence } \\
\text { (\%) }\end{array}$ & $\begin{array}{c}\text { Overall } \\
\text { Survival } \\
\text { (\%) }\end{array}$ \\
\hline Keys et & 132 & none & 5 & 8 & 89 \\
al. (7) & 128 & ERT & & 4 & 89 \\
\hline Creutzberg & 106 & none & 10 & 9 & 81 \\
et al. (8) & 92 & ERT & & 10 & 82 \\
\hline Aalders & 126 & ICRT & 5 & 6 & 98 \\
et al. (9) & 131 & ICRT+ERT & & 9 & 93 \\
\hline
\end{tabular}

AdjRT: adjuvant radiotherapy; RT: radiotherapy; ERT: external pelvic radiotherapy; ICRT: intracavitary radiotherapy

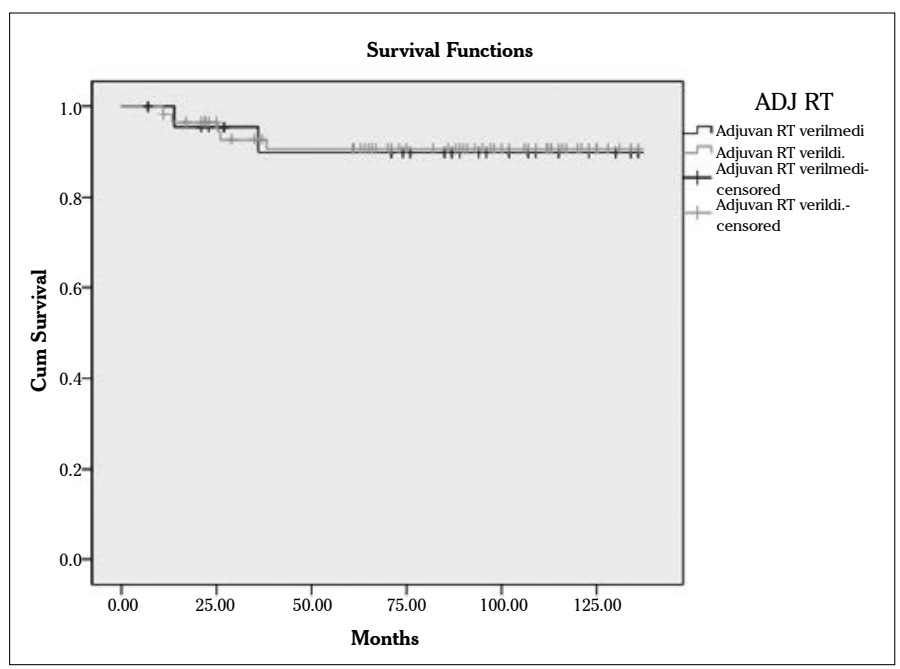

Figure 1. Disease-free survival

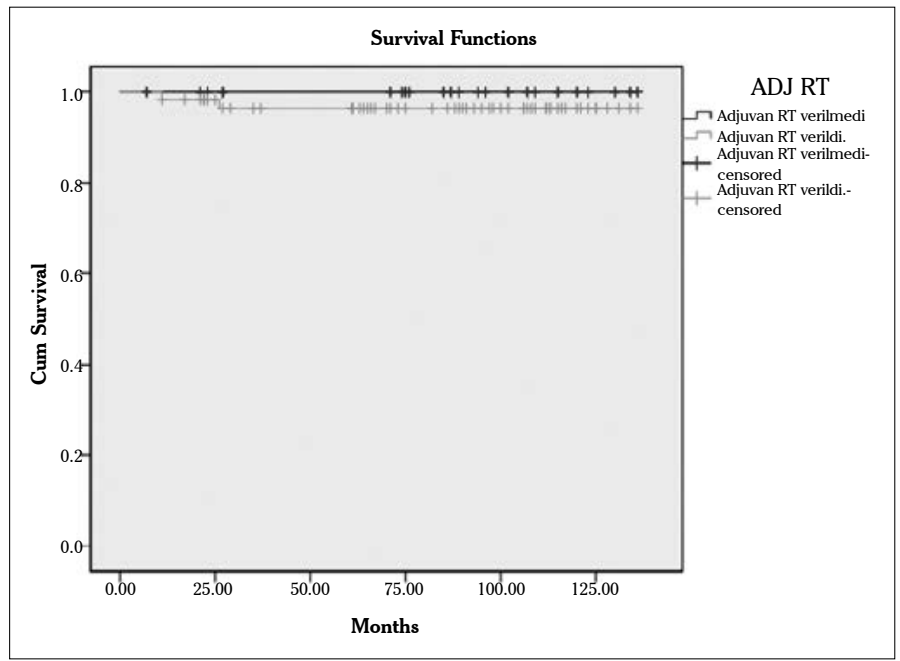

Figure 2. Overall survival at 5 years

although a firm consensus has not been reached, authors predominantly have stated that adjuvant radiotherapy lowers the local recurrence rates but does not change the survival rates (Table 5) $(7,8)$. The results of the Post Operative Radiation Therapy in Endometrial Carcinoma (PORTEC) study were published 
in the year 2000, indicating the efficiency of radiotherapy in local recurrence control (8). In the PORTEC study Creutzberg et al. (8) reported that the comparison of the radiotherapy group with the control group for local and regional relapse has demonstrated local recurrence rates of $4 \%$ and $15 \%$, respectively $(p<0.0001)$; however, the survival rates were found to be similar in both groups. In conclusion, the research has emphasized that only patients at a high risk for recurrence should receive adjuvant pelvic radiotherapy postoperatively. Another remarkable finding in the PORTEC study Creutzberg et al. (8) reported the high efficiency of salvage radiotherapy for local recurrence control in patients without previous exposure to radiotherapy. In a similar study by Straughn et al. (12), patients with a surgically staged endometrial cancer restricted to the uterine corpus were evaluated; the results of the study have revealed that patients had a low risk of recurrence, and most of the recurrent cases were successfully treated with radiotherapy.

In a meta-analysis of seven studies conducted by Kong et al. (13), adjuvant radiotherapy was found to decrease local recurrence rates in stage 1 endometrial cancer, but it has a deleterious effect on overall survival because of its toxicity. According to the results of a similar study conducted by Kocak et al. (14) on the long-term benefits of postoperative adjuvant radiotherapy at stage $1 \mathrm{~b}$ grade 2 endometrial cancer, the 3 -year disease-free survival rates between the adjuvant radiotherapy group and no treatment group were $96.6 \%$ and $80.5 \%$, respectively $(\mathrm{p}<0.01)$. Other trials showed that brachytherapy did not improve overall survival or recurrence in comparison with observation alone and was associated with significantly more toxicities, including vaginal, urogenital, and gastrointestinal adverse effects $(15,16)$. Based on these results, observation following surgery was recommended for the majority of patients with low-risk endometrial cancer.

In our study, we have detected no survival benefit for patients after radiotherapy, and the recurrence rates were found to be lower than other results reported in similar previous studies (13). In these studies, patients diagnosed with stage la grade 3 or stage $1 \mathrm{~b}$ disease were also included, which could be interpreted as a possible reason for an increase in local recurrence rates. An additional factor may be that, compared with our study, a relatively lower proportion of patients underwent lymph node dissection in these trials. The comparison of both groups for recurrence rates has revealed no significant difference $(p=0.485)$, indicating that the adjuvant radiotherapy had no influence on local recurrence in early-stage endometrial endometrioid adenocarcinoma patients.

The dosage and type of postoperative radiotherapy (e.g., pelvic external beam radiotherapy and vaginal intracavity brachytherapy) were not recorded in the medical charts of patients; thus, these data could not be retrieved. This fact has been recognized as a potential limitation for the comparison of our findings regarding the influence of radiotherapy on survival and local recurrence rates.

The aim of the treatment applied in low-risk early-stage endometrial cancer is to decrease treatment-related overall morbidity without compromising the survival rates (17). Epidemiologic studies have reported a $25 \%$ increase in the relative risk of secondary malignancies after radiation for endometrial cancer; young individuals are particularly under high risk (18). Therefore, radiotherapy should certainly be applied with caution, particularly in younger women with a long life expectancy. In conclusion, this study, the application of postoperative radiotherapy has been found to have no significant influence on the survival rates in low-risk patients with a diagnosis of FIGO stage 1a grade 2 endometrial endometrioid adenocarcinoma. The local recurrence rates were similar in both groups and remarkably lower than the results in previous studies.

Considering the findings of our study and other relevant trials reported previously, we believe that the use of adjuvant radiotherapy is not required in patients of the low-risk group (stage 1a, grade 2) because it fails to improve the survival rates and induces radiation toxicity in susceptible individuals. In this patient group, a close observation should be performed following the primary surgery, and radiotherapy should be considered as a very efficient recovery treatment modality in patients with vaginal relapse.

Ethics Committee Approval: Ethics committee approval was received for this study from the Local ethics committee of Aegean Obstetrics and Gynecology Education and Research Hospital.

\section{Informed Consent: $N / A$.}

Peer-review: Externally peer-reviewed.

Author Contributions: Concept - H.I., M.H., Y.Y.; Design - H.I., M.H., Y.Y.; Supervision - Y.Y., M.H.; Resource - H.I., Y.Y., M.H.; Materials - H.I., G.Ş.E., M.H., Y.Y., T.G.; Data Collection and/or Processing H.I., G.S..E., T.G.; Analysis and/or Interpretation - H.I., G.S..E., A.G.K.; Literature Search H.I., G.S.E., T.G., A.G.K.; Writing - H.I., G.Ş.E., Y.Y.; Critical Reviews - H.i.., G.S.E., Y.Y., A.G.K.

Conflict of Interest: No conflict of interest was declared by the authors.

Financial Disclosure: The authors declared that this study has received no financial support.

\section{References}

1. Creasman WT, Morrow CP, Bundy BN, Homesley HD, Graham JE, Heller PB. Surgical pathologic spread patterns of endometrial cancer. A Gynecologic Oncology Group Study. Cancer 1987; 60: 2035-41. [CrossRef]

2. Creasman WT, Kohler MF, Odicino F, Maisonneuve P, Boyle P. Prognosis of papillary serous, clear cell, and grade 3 stage I carcinoma of the endometrium. Gynecol Oncol 2004; 95: 593-6. [CrossRef]

3. Grigsby PW, Perez CA, Kuten A, Simpson JR, Garcia DM, Camel HM, et al. Clinical stage I endometrial cancer: Results of adjuvant irradiation and patterns of failure. Int J Radiat Oncol Biol Phys 1991; 21: 379-85. [CrossRef]

4. Grigsby PW, Perez CA, Kuten A, Simpson JR, Garcia DM, Camel $\mathrm{HM}$, et al. Clinical stage I endometrial cancer: Prognostic factors for local control and distant metastases and implications of the new FIGO surgical staging system. Int J Radiat Oncol Biol Phys 1992; 22: 905-11. [CrossRef]

5. National Cancer Institute. SEER stats fact sheets: corpus and uterus, NOS. Available from: http://seer.cancer.gov/statfacts/html/ corp.html;2012.

6. Onsrud M, Cvancarova M, Hellebust TP, Tropé CG, Kristensen GB, Lindemann K. Long-Term Outcomes After Pelvic Radiation for 
Early-Stage Endometrial Cancer. J Clin Oncol 2013; 31: 3951-6. [CrossRef]

7. Keys HM, Roberts JA, Brunetto VL, Zaino RJ, Spirtos NM, Bloss JD, et al. A phase III trial of surgery with or without adjunctive external pelvic radiation therapy in intermediate risk endometrial adenocarcinoma: A Gynecologic Oncology Group study. Gynecol Oncol 2004; 92: 744-51. [CrossRef]

8. Creutzberg CL, van Putten WL, Koper PC, Lybeert ML, Jobsen JJ, Wárlám-Rodenhuis $\mathrm{CC}$, et al. Surgery and postoperative radiotherapy versus surgery alone for patients with stage- 1 endometrial carcinoma: multicentre randomised trial. PORTEC Study Group. Post Operative Radiation Therapy in Endometrial Carcinoma. Lancet 2000; 355: 1404-11. [CrossRef]

9. Aalders J, Abeler V, Kolstad P, Onsrud M. Postoperative external irradiation and prognostic parameters in stage I endometrial carcinoma. Obstet Gynecol 1980; 56: 419-26.

10. FIGO (International Federation of Gynecology and Obstetrics). FIGO stages, 1988 revision. Gynecol Oncol 1989; 35: 125-7.

11. Pecorelli S. Revised FIGO staging for carcinoma of the vulva, cervix, and endometrium. Int J Gynaecol Obstet 2009; 105: 103-4. [CrossRef]

12. Straughn JM Jr, Huh WK, Kelly FJ, Leath CA $3^{\text {rd }}$, Kleinberg MJ, Hyde J Jr, et al. Conservative management of stage I endometrial carcinoma after surgical staging. Gynecol Oncol 2002; 84: 194-200. [CrossRef]
13. Kong A, Johnson N, Kitchener HC, Lawrie TA. Adjuvant radiotherapy for stage I endometrial cancer. Cochrane Database Syst Rev 2012; 4: CD003916. [CrossRef]

14. Kocak M, Eren M, Naki MM, Aksu A, Celik H, Ozkan A, et al. Long Term Benefits of Post-surgical Adjuvant Radiotherapy Among Subpopulation of Patients with Stage IB Grade 2 Endometrial Cancer. International Journal of Hematology and Oncology 2011; 21: 71-9. [CrossRef]

15. Noyes WR, Bastin K, Edwards SA, Buchler DA, Stitt JA, Thomadsen $\mathrm{BR}$, et al. Postoperative vaginal cuff irradiation using high dose rate remote afterloading: a phase II clinical protocol. Int J Radiat Oncol Biol Phys 1995; 32: 1439-43. [CrossRef]

16. Sorbe B, Straumits A, Karlsson L. Intravaginal high-dose-rate brachytherapy for stage I endometrial cancer: a randomized study of two dose-per-fraction levels. Int J Radiat Oncol Biol Phys 2005; 62: 1385-9. [CrossRef]

17. Creutzberg CL, van Putten WL, Koper PC, Lybeert ML, Jobsen $\mathrm{JJ}$, Warlam-Rodenhuis CC, et al. The morbidity of treatment for patients with Stage I endometrial cancer: results from a randomized trial. Int J Radiat Oncol Biol Phys 2001; 51: 1246-55. [CrossRef]

18. Kumar S, Shah JP, Bryant CS, Awonuga AO, Imudia AN, Ruterbusch $\mathrm{JJ}$, et al. Second neoplasms in survivors of endometrial cancer: Impact of radiation therapy. Gynecol Oncol 2009; 113: 233-9. [CrossRef] 